\title{
Research on Teaching Reform of MCU Course Based on Proteus
}

\author{
Cao Pan ${ }^{1}$ \\ ${ }^{1}$ School of Information Science and Engineering, \\ Changzhou University, \\ Changzhou, 213164, China \\ Qi-cai Cheng ${ }^{1}$ \\ ${ }^{1}$ School of Information Science and Engineering, \\ Changzhou University, \\ Changzhou, 213164, China
}

\author{
Hui Ding ${ }^{1}$ \\ ${ }^{1}$ School of Information Science and Engineering, \\ Changzhou University, \\ Changzhou, 213164, China \\ Meng Lv ${ }^{1}$ \\ ${ }^{1}$ School of Information Science and Engineering, \\ Changzhou University, \\ Changzhou, 213164, China
}

\begin{abstract}
Principle and application of single chip microcomputer" is an important course for electronic information specialty. In view of the problems existing in the traditional teaching, combined with Proteus ,keil and virtual reality technology from two aspects of the teaching method and experiment measures, elaborated teaching reform in the new method based on Proteus, which will innovate classroom teaching mode, enrich the contents of the practice teaching, improve the teaching effect, stimulate the students' learning interest, and cultivate the students' practical innovation ability.
\end{abstract}

Keywords: Proteus; MCU; Teaching Reform

\section{Introduction}

"The principle and application of single chip microcomputer" is an important course of electronic and information specialty. It is a combination of theory and practice. The course mainly introduces a typical type of microcomputer hardware structure, instruction system, programming method and common peripheral interface chip, software and hardware design method of MCU application system.

In order to improve the teaching effect of MCU course, this paper puts forward the teaching reform of the teaching and simulation experiment based on Proteus. Through a lot of teaching examples and experimental simulation demo, can combine theoretical teaching and practice well, enhance students' perceptual knowledge.; at the same time in the teaching practice by introducing the Proteus simulation experiment, is conducive to the cultivation of students' practice ability, innovation ability and comprehensive use of knowledge in building a practical MCU application system[1-2].

\section{Proteus software}

Proteus is the design and simulation platform of analog circuit, digital circuit and analog digital mixed circuit. And it is also the advanced design and simulation platform of single chip computer system.It truly realized the design and simulation process from schematics and circuit design, circuit analysis and simulation, MCU code level debugging and simulation, system test and the function verification to the formation of PCB on the computer. It has been more and more popular in the teaching of SCM, engineering and technical personnel, as well as a large number of universities students and single-chip technology enthusiasts[3].

Proteus can design and simulation system which is composed of ARM7, 805x, PIC, AVR and other series $\mathrm{MCU}$; there are thousands of components, simulation model; oscilloscope, logic analyzer, such as more than 10 kinds of virtual instrument, signal excitation source, ASF advanced diagram simulation. Proteus also provides an environment for editing source program, generating target code, debugging, and integrated development environment with the third party integrated development software. Proteus provides a complete virtual laboratory for teaching and application of MCU. In particular: due to the parameters according to the manufacturers to provide technical documents to establish the Proteus simulation model, so the simulation is very close to the actual, which enables it to transcend the "virtual", has become a practical teaching, research and development platform[4-7].

\section{MCU Teaching Reform Based on Proteus}

\subsection{MCU course teaching reform}

\section{(1)Problems in theoretical teaching}

MCU course involves a wide range of knowledge, and the requirements of abstract thinking and logical thinking are very high, students feel difficult to learn, teachers feel difficult to teach. Therefore, the teaching content should be 
displayed clearly to the students. In the past, the teacher generally introduced the experimental board or simulator in the classroom, and done the demonstration experiment to the students. But the teaching effect was often not ideal, a small experimental board and the emulator is very difficult to see clearly, can not let all the students observe the effect . So the traditional teaching was lack of effective presentation method, and was the basic language to describe the pure theory, was lack of objective vectors, made the listener not well understood.

\section{(2)MCU Course Teaching Based on Proteus}

The wide application of single chip computer makes the virtual simulation technology develop rapidly. Keil software is the development of MCU software, which supports macro assembler and C language programming, connection and simulation debugging, of 51 series MCU and other popular micro controller; Circuit design and analysis software of Proteus can complete the design of hardware circuit schematic, PCB circuit board wiring and circuit simulation, can also realize the software and hardware co simulation combining with MCU software.So we can write MCU programs by keil software, design corresponding hardware circuit by Proteus software, and then load the simulation programs into the micro controller simulation through the association of two software. In the end, we can build a MCU virtual laboratory on the computer to help students to practice and study.

The application of Proteus in MCU course teaching has the following characteristics:First,it can introduce theoretical knowledge from a combination of hardware and software, and the view of engineering application, enhance the student's perceptual knowledge, stimulate students' learning interest and initiative, grasp the theoretical knowledge and improve the teaching quality further more.Second,hardware circuit can be changed at any time according to the teaching content, it can modify the program at any time.and display the results of the simulation, and help students understand the theory knowledge. The practice proves that the effect is very good.

\subsection{MCU practice teaching reform}

\section{(1)Problems in the practice teaching}

In many universities and colleges, the single chip microcomputer laboratory is usually used with the experimental box or the test board, which is convenient to take this method, but it also has shortcomings. First of all, the use of single chip microcomputer test box is finished, the circuit connection is already fixed connection, the content can only stay in the level of demonstration and validation experiments. Students are very difficult to participate in the design, but also can not fully understand the actual connection of the hardware circuit, do not get the training and improvement. Secondly, the type of micro controller is different, and resources in experimental box is limited. There is impossible to include all kinds of MCU and peripheral circuit in a laboratory. With the rapid development of MCU technology, many universities and colleges are lagging behind, and the purchase of equipment lead to a serious waste of money. Third, in the process of experiment, there are many instruments to be used, which can easily cause damage to equipment, and need a lot of maintenance work. So the traditional practice teaching of MCU is a big problem.

\section{(2)Practical teaching based on Proteus}

In view of the problems existing in the practice teaching of "Microcomputer Principle and application", using keil, Protues and virtual reality technology to construct virtual practice teaching system, combined with the actual situation to realize the open practice teaching and improve the practice teaching environment, reform practice teaching mode, optimize practice teaching content and improve the practice teaching level, cultivate students' comprehensive application knowledge ability, practice ability and innovation ability.

Relying on the open virtual laboratory based on the Proteus, Keil and virtual reality technology. Design multiple different levels of experimental environment and experimental methods for the same experiment, innovate practice teaching methods and means, realize the diversification, design and research of the experiment course.The verification experiment can be enable students to learn the basic skills practice, cultivate students' operation ability and interest in experiment; Comprehensive experiment with several related courses combining content, with a complex experiment content, with a diversity of experimental methods and experimental means, which can cultivate students' ability of theory and practice. The design experiment has the characteristics of the experimental method, it is the ability to develop students' comprehensive use of knowledge and independent analysis and problem solving skills. Exploring experiment is characterized by the experimenter to learning initiative and the content of exploration, usually the teacher gives the subject to students to make their own design, independent completion of the experiment, the aims is to cultivate students' interest in scientific research and scientific inquiry ability. Innovative experiment with multiple attributes about the experimental method, it can cultivate students' innovative spirit and ability through the way that students independently put forward the experimental subjects, design the experimental program, complete the experimental process.The experimental process of the virtual experiment system based on Proteus is shown in Fig 1. 


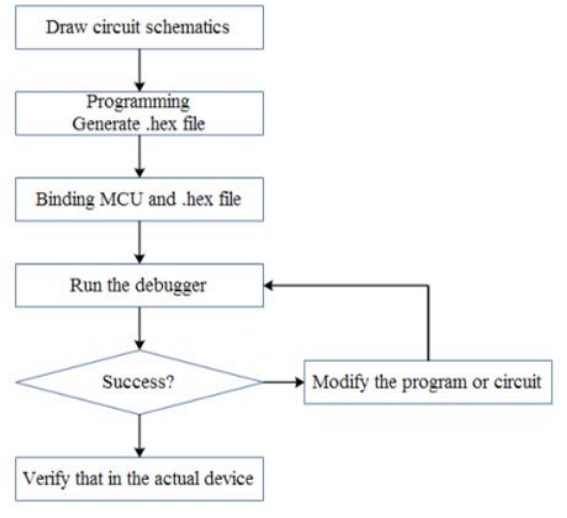

Fig. 1: Experiment process flow chart of virtual experiment system.

\section{Application examples of Proteus in integrated practice of $\mathrm{MCU}$}

Here is a 8 channel data acquisition experiment design, for example, the practice teaching process of MCU based on Proteus is introduced in this.

First, complete the design of the whole hardware circuit by Proteus software. Including MCU minimum system, independent key module, 6 digital tube display module, DS18B20 data acquisition module. 3 buttons are designed: MODE key to achieve automatic / manual switch; UP key to achieve manual mode, display channel plus 1; DOWN key to achieve manual mode, display channel minus 1 . In automatic mode, every 3 seconds to switch a DS18B20 measurement channel.Then write source code and save *. C file, compiling, debugging, and to observe whether the change of the relevant register is correct., if correct, generating the *.hex file by Keil software.Finally, run Proteus, load the *.hex file, and then use the tool bar to start the emulator to observe whether the simulation results meet the design requirements. Simulation results are shown in Fig 2.

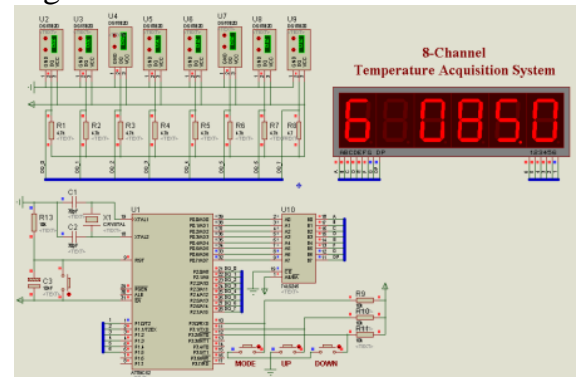

Fig. 2: Simulation results.

Students need to complete the design and debugging of hardware and software. In the process of debugging, students should analyze the problems which appear in the experiment, and realize the further deepen understanding of the software and hardware design of $\mathrm{MCU}$ application system in the process of solving problems. So as to further develop the students' ability to solve practical engineering problems.

\section{Conclusion}

Proteus simulation software in the MCU curriculum teaching reform is feasible, which has more obvious advantages: Teachers in the classroom teaching can get rid of instrument and equipment of the bound, the use of simulation software can be flexible to combine circuit, improve the quality of teaching; students can design their own hardware or software programming and use the Proteus simulation software to finish virtual experiment. In short, the use of Proteus simulation software can improve the students' learning interest, expand the students' design ideas, strengthen students' engineering practice ability.

\section{Acknowledgment}

The author gratefully acknowledge the financial support of the Teaching and education project(Research on the integrated platform of MCU course based on the training plan of excellent engineers,GJY2014058) of Changzhou University.(The research and practice of the construction of computer specialty laboratory in the Independent College,2014HDJY12) of Huaide College, Changzhou University.

\section{References}

[1] Yuan Feng-wei, Zhao Li-hong, Zhu Hui-lin, Zhang Ying, "Reform on Teaching Experiment of MCU Course Based on Proteus," Research and Exploration in Laboratory, pp. 75-78, 2007, 26(12).

[2] Wang Fan, "Research and Application of Proteus in Graduation Design of Electronic Engineering Major," Experimental Technology and Management, pp. 112114, 2014, 31(4).

[3] Wang Xiao-hui, "Instructional Curriculum Design of Humidity Measurement Based on HS1101 System," Journal of EEE, pp. 52-54, 2015, 37(1).

[4] Liu De-quan, "Design and Simulation of Intelligent Greenhouse Humidity and Temperature Measurement Experiment System," Research and Exploration in Laboratory, pp. 92-95, 2015, 34(2).

[5] Ye Ji-ying, Li Lin, Yao Qi-guo, Xu Le, "Application of Proteus in Electric Information Experiment Teaching Reform," Journal of AnHui Electrical Engineering Professional Technique College, pp. 118-121, 2015, 20(1).

[6] Liu Xin-hong, Guo Fu-tian, Sun Zheng-xing, Zeng Li-li, "The application about Proteus emulation technique on teaching of MCU," Experimental Technology and Management, pp. 96-98, 2007, 24(3).

[7] Su Bian-lin, Zhu Zhi-pin, Yuan Wei, "MCU Simulation Teaching Based on Proteus," Research and Exploration in Laboratory, pp. 75-78, 2009, 28(4). 